\title{
Evaluation of Sperm Viability and Acrosomal Integrity by Flow Cytometry Analysis in Jersey Crossbred Bulls
}

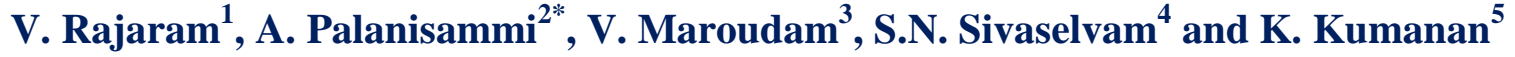 \\ ${ }^{1}$ Department of Animal Biotechnology, Madras Veterinary College, Tamil Nadu Veterinary and \\ Animal Sciences University, Chennai-7, Tamil Nadu, India \\ ${ }^{2}$ Education Cell, Madras Veterinary College, TANUVAS, Chennai-7, Tamil Nadu, India \\ ${ }^{3}$ Translational Research Platform for Veterinary Biologicals, Chennai - 51, Tamil Nadu, India \\ ${ }^{4}$ Madras Veterinary College, TANUVAS, Chennai-7, Tamil Nadu, India \\ ${ }^{5}$ Centre for Animal Health Studies, TANUVAS, Chennai-51, Tamil Nadu, India \\ *Corresponding author
}

A B S T R A C T

\section{Keywords}

Jersey crossbred bulls, Fertility, Flow cytometry, Sperm for viability, Acrosomal integrity.

\section{Article Info}

Accepted:

04 September 2017

Available Online:

10 October 2017
Flow cytometry based evaluation of sperm parameters is advantageous over the traditional microscope based evaluation. Many sperm parameters can be measured within short time period and with high accuracy. For this study, semen from six Jersey crossbred bull were collected. Semen parameters like sperm for viability and acrosomal integrity were analyzed by flow cytometry. Sperm for viability measured by the propidium iodide staining indicated that Bull No: 3 have the highest number of viable spermatozoa with 82.89 per cent followed by $82.18,80.26,79.43,75.20$ and 70.73 for Bull No: 1, 5, 2, 6 and 4 respectively. Acrosomal integrity of the sperm sample were determined by fluorescein isothiocynate (FITC) labelled with Peanut agglutinin (PNA) staining. The percentage of viable sperm, non-viable sperm, viable intact sperm, viable damage sperm and viable damage and non-viable sperm was ranged from 75.12 to $82.28,17.72$ to $30.66,58.55$ to $78.48,3.80$ to 10.80 and 21.52 to 41.45 respectively. Chi's square analysis of the semen samples indicated that there was a significant difference among bulls with respect to both the sperm viability and acrosomal integrity $(\mathrm{P}<0.01)$.

\section{Introduction}

Microscopic evaluation of the semen quality is a time consuming process and the result depends on only few hundred cells. One of the advancement in the semen evaluation technique is the flow cytometry based assessment. It not only generates data on large pool of cells than microscopic evaluation, but also various parameters can be measured with each of this cell (Melamed et al., 1979; Loken, 1980). Flowcytometry is a high throughput technique which is able to analyze thousands of cells within seconds. It is a fast, accurate, highly sensitive and highly repeatable technique. Changes in the sperm surface induced by sperm capacitation, morphological abnormalities present in the sperm sample can be determined using flow cytometry (Bochenek et al., 2001). It can analyze significantly more sperm per sample (up to 10,000) than standard semen analysis (Christensen et al., 2004). In addition to these, more parameters like sperm viability, 
membrane integrity (Evenson et al., 1982; Garner and Johnson, 1995; Garner et al., 1994), mitochondrial function and membrane potential (Evenson et al., 1982; Garner et al., 1997; Graham et al., 1990) chromatin structure (Bochenek et al., 2001;Evenson et al., 1980), and acrosomal status (Graham et al., 1990; Nagy et al., 2003; Thomas et al., 1997) can also be evaluated. It is also possible to acquire data from different subpopulations within a sample, thereby helps in the evaluation of heterogeneous population evaluation which were in different states of activation. It has a high degree of experimental repeatability to work with both small and large sample size (Silva and Gadella, 2006).

Supravital stain eosin/nigrosine or Propidium iodide (PI) is used to study the intactness of the spermatozoa using flowcytometry. The Propidium iodide dye cannot pass through the intact plasma membrane. But it passes through the degenerated spermatozoa and stains its nuclei (Garner et al., 1986). The most popular viability stains for spermatozoa evaluation are propidium iodide (PI) and ethidium homodimer (EH) stains. The advantages of these stains are they can be excited using 488nm laser; easy to use and it's a quick or rapid staining method. These stain enter into the cell via a broken plasmalemma, emitting red fluorescence (PI: $636 \mathrm{~nm}$; EH: $617 \mathrm{~nm}$ ) when they bind to nucleic acids (Gillan et al., 2005).

Spermatozoa must maintain an intact acrosome upto which it binds to the zona pellucida of oocytes. Upon binding with oocyte, acrosomal enzymes are activated and they digest a hole through zona pellucida thereby allowing the sperm cells to access the oolemma (Yanagimachi, 1981). Usually by staining, the acrosomal status was evaluated. To study the acrosomal status of larger population of sperm, the flurometric and flowcytometry (Graham, 2001; Purdy and
Graham, 2004) have been used. Flurometric analysis of the acrosomal integrity involves labeling of the acrosome with fluorescent lectins. For this, commonly Pisum sativum agglutinin (PSA) derived from the pea plant and Arachis hypogaea agglutinin (PNA) derived from the peanut plant are the most commonly used lectins for fluorescent labelling because of their specificity (Graham, 2001).

The present study was aimed to evaluate the sperm for viability and acrosomal integrity collected from six Jersey crossbred bulls by flow cytometry analysis.

\section{Materials and Methods}

\section{Collection of semen samples}

Semen from six Jersey crossbred bulls were collected by artificial vagina and collected semen samples were covered with aluminium foil and kept in the beaker containing warm water at $37^{\circ} \mathrm{C}$ and transported to Centralized Embryo Biotechnology Unit and Translational Research Platform for Veterinary Bilogicals (TANUVAS), Madhavaram milk colony for further analysis

\section{Sperm preparation}

The sperm and seminal plasma were separated immediately after collection by diluting ten times with TALP medium and washing twice by centrifugation (1200 rpm for five min) to collect the sperm pellet. The sperm pellet was resuspended at $100 \times 10^{6}$ cells/ml as per protocol mentioned in Graham et al., (1990).

\section{Evaluation of sperm for viability}

Sperm for viability was determined by propidium iodide (PI). A $10 \mu \mathrm{l}$ volume of PI was added to $400 \mu \mathrm{l}$ sperm suspension and the sample was incubated for five min. add one 
$\mathrm{ml}$ of sheath fluid and filter the content through a $40 \mu \mathrm{m}$ pore size cell strainer to remove the large debris and the cells were analysed by flow cytometry to evaluate the percentage of the dead cells. Flow cytometer analysis was performed by using Beckman Coulter fitted with a bevelled tip. The PI was excited at $488 \mathrm{~nm}$ by an argon laser at $100 \mathrm{~mW}$ of power. Fluorescence emission was measured with a $515 \mathrm{~nm}$ long-pass filter and with a 610 long-pass filter for PI detection (Graham et al., 1990)

\section{Evaluation of acrosomal integrity}

Acrosomal integrity of the bull sperm was evaluated by fluorescein isothiocynate (FITC) - labelled with Peanut agglutinin (PNA) and assayed by flowcytometry to assess the percentage of cells without an intact acrosome. A $10 \mu \mathrm{l}$ of PI and $20 \mu \mathrm{l}$ FITC labelled with PNA were added to the sperm samples in the ratio of $0.5 \mu \mathrm{g}$ lectin per one million cells. Add one $\mathrm{ml}$ of sheath fluid and filter the content through a $40 \mu \mathrm{m}$ pore size cell strainer to remove the large debris and the cells were analysed by flow cytometry to evaluate the acrosomal damage along with the percentage of the dead cells. Flow cytometric analysis was performed with $560 \mathrm{~nm}$ beamsplitting filter and a $525 \mathrm{~nm}$ band-pass filter for FITC-PNA detection. Within the population, a subpopulation of $\mathrm{AR}$ cells bound PNA, resulting in a sharp fluorescent emission in forward scatter (Graham et al., 1990 and Nagy et al., 2003).

\section{Results and Discussion}

\section{Evaluation of sperm for viability by flowcytometry}

The evaluation of sperm for viability in the collected sperm sample was determined by propidium iodide which was displayed in table 1. There is a high significant difference $(\mathrm{P}<0.01)$ in the sperm viability between the bulls. Among the six bulls, Bull No 3 has higher percentage of viable spermatozoa (82.89 per cent) followed by $82.18,80.26$, 79.43, 75.20 and 70.73 for Bull No: 1, 5, 2, 6 and 4 respectively. The percentage of dead sperm was 29.27, 24.80, 20.57, 19.74, 17.82 and 17.11 for Bull No: 4, 6, 2, 5, 1 and 3 respectively.

\section{Acrosomal integrity by flowcytometry}

Acrosome integrity was analyzed using FITC labeled PNA is shown in Table No 2. It binds with the acrosomal content with more affinity. The percentage of viable intact spermatozoa was found to be higher in semen sample of Bull No 3 with 78.48 per cent whereas the high percentage of viable damage spermatozoa was found in Bull No 4 with 10.80 per cent.

The percentage of viable intact sperm in Bull No 4 was less for sperm capacitation. Higher percentage of acrosomal viable spermatozoa (82.28 per cent) was observed in Bull No 3 followed by Bull No 1, Bull No 2, Bull No 5, Bull No 6 and Bull No 4 with the percentage of $81.83,79.68,79.15,75.12$ and 69.34 , respectively. The result of Chi-square test revealed that the semen samples of different bulls showed high significance difference $(\mathrm{P}<0.01)$ with respect to the acrosomal integrity in spermatozoa.

Established microscopic procedures for evaluating populations of sperm cells are hindered by involved preparation and timeconsuming analysis; consequently, sample size is small. Flow cytometry offers the possibility of objectively measuring thousands of cells for multiple characteristics in a short time with minimum preparation (Graham et al., 1990). The flow cytometry based analysis is less likely to generate errors and its multiple sperm parameter analysis helps in the better understanding of the spermatozoan functionality (Petrunkina et al., 
2007). the flowcytometry based spermatology is a pioneering technique that aids in the routine assessment of animal semen prior to breeding. It will also help in the better understanding of the sperm physiology and functionality (Hossain et al., 2011).

The flowcytometry based detection of subfertile bull segregation with the identification of abnormal spermatozoa shown to be outstanding technique than the regular methods of semen analysis (Kennedy and Sutovsky, 2011).
Evaluation of sperm for viability by flowcytometry

In the present study, the percentage of viable and non-viable sperm by flowcytometry was ranged from 70.73 to 82.89 and 17.11 to 24.80 respectively. These results were in accordance with Graham et al., (1990) who studied sperm cell viability, acrosomal integrity and mitochondrial function using flow cytometry and found that PI stained cells (red- non viable) ranging from seven per cent to 41 per cent.

Table.1 Evaluation of sperm for viability

\begin{tabular}{|c|c|c|c|}
\hline Bull No & Total sperm & Viable sperm & Non-viable sperm \\
\hline 1 & 61338 & $50408(82.18)$ & $10930(17.82)$ \\
\hline 2 & 61542 & $48885(79.43)$ & $12657(20.57)$ \\
\hline 3 & 61078 & $49736(82.89)$ & $11342(17.11)$ \\
\hline 4 & 61235 & $43312(70.73)$ & $17923(29.27)$ \\
\hline 5 & 61589 & $49436(80.26)$ & $12153(19.74)$ \\
\hline 6 & 60977 & $45854(75.20)$ & $15123(24.80)$ \\
\hline \multicolumn{2}{|c|}{ Chi square test $\left(\chi^{2}\right)$} & \multicolumn{2}{|c|}{$348.82^{* *}$} \\
\hline
\end{tabular}

Note: Figures in parenthesis indicate the percentage value.

Table.2 Evaluation of Acrosomal integrity by flowcytometry

\begin{tabular}{|c|c|c|c|c|c|c|}
\hline $\begin{array}{c}\text { Bull } \\
\text { No }\end{array}$ & $\begin{array}{c}\text { Total } \\
\text { sperm }\end{array}$ & $\begin{array}{c}\text { Viable } \\
\text { sperm }\end{array}$ & $\begin{array}{c}\text { Non-viable } \\
\text { sperm }\end{array}$ & $\begin{array}{c}\text { Viable } \\
\text { intact } \\
\text { sperm }\end{array}$ & $\begin{array}{c}\text { viable } \\
\text { damage } \\
\text { sperm }\end{array}$ & $\begin{array}{c}\text { viable damage } \\
\text { and non-viable } \\
\text { sperm }\end{array}$ \\
\hline 1 & 61739 & $\begin{array}{c}50523 \\
(81.83)\end{array}$ & $\begin{array}{c}11216 \\
(18.17)\end{array}$ & $\begin{array}{c}46482 \\
(75.28)\end{array}$ & $3951(6.40)$ & $15167(24.57)$ \\
\hline 2 & 61799 & $\begin{array}{c}49243 \\
(79.68)\end{array}$ & $\begin{array}{c}12556 \\
(20.32)\end{array}$ & $\begin{array}{c}43496 \\
(70.38)\end{array}$ & $5747(9.29)$ & $18303(29.62)$ \\
\hline 3 & 61388 & $\begin{array}{c}50512 \\
(82.28)\end{array}$ & $\begin{array}{c}10876 \\
(17.72)\end{array}$ & $\begin{array}{c}48179 \\
(78.48)\end{array}$ & $2333(3.80)$ & $13209(21.52)$ \\
\hline 4 & 61380 & $\begin{array}{c}42567 \\
(69.34)\end{array}$ & $\begin{array}{c}18813 \\
(30.66)\end{array}$ & $\begin{array}{c}35938 \\
(58.55)\end{array}$ & $6629(10.80)$ & $25442(41.45)$ \\
\hline 5 & 61846 & $\begin{array}{c}48951 \\
(79.15)\end{array}$ & $\begin{array}{c}12895 \\
(20.85)\end{array}$ & $\begin{array}{c}44562 \\
(72.05)\end{array}$ & $4389(7.10)$ & $17284(27.94)$ \\
\hline 6 & 61321 & $\begin{array}{c}46068 \\
(75.12)\end{array}$ & $\begin{array}{c}15253 \\
(24.88)\end{array}$ & $\begin{array}{c}40135 \\
(65.45)\end{array}$ & $5933(9.68)$ & $21186(34.55)$ \\
\hline \multicolumn{7}{|c|}{ Chi square test $\left(\chi^{\mathbf{2}}\right)$} \\
\hline
\end{tabular}

Note: Figures in parenthesis indicate the percentage value. 
Fig.1 Examples of flow cytometry analysis for assessing spermatozoa physiology

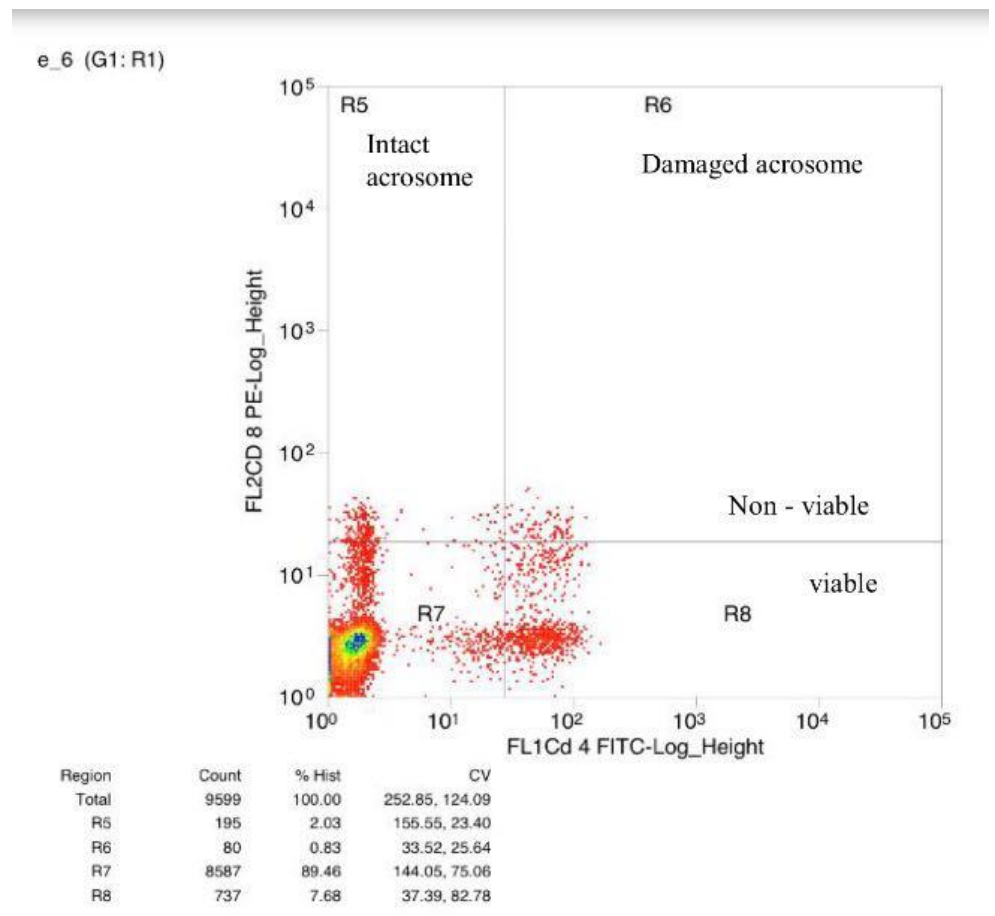

Flow cytometry image of a PI / FITC-PNA stain. Spermatozoa can be divided into intact / damaged acrosome and viable / non-viable, according to their green and red fluorescence.

Alessandra et al., (2010) studied the stallion sperm for viability by flow cytometry and was ranged from $96.9 \pm 2.64$ (Mean $\pm \mathrm{SE}$ ) and ranged from 92 to 99 per cent. Cheryl et al., (1997) reported that the mean percentage of motile spermatozoa (MOT), quantified using the microscopic method and the mean percentages of fluorometric estimates of viability, SYBE-14, LYSO-G and SYTO-17 were 66 per cent, 51 per cent, 48 per cent and 42 per cent respectively. Both MOT and SYTO - 17 differed from values obtained with all other methods. The mean percentages of LYSO - G stained spermatozoa and SYBR - 14 stained spermatozoa did not differ. Garner and Johnson (1995) studied the viability assessment of bull sperm and reported that $66.6 \pm 5.7$ and $25.4 \pm 4.5$ per cent viable and non-viable bull sperm respectively was observed when the sperm stained with SYBR-14 (green-viable) and PI (red- non viable)
PI cannot pass through an intact plasma membrane, but passes into and stains the nuclei of degenerated spermatozoa (Garner $e t$ al., 1986). Assays using PI and eosin/nigrosin stains for intact plasma membranes produced nearly equivalent results indicating that PI is an accurate supravital stain for sperm analyzed by flowcytometry.

\section{Evaluation of acrosomal integrity by flowcytometry}

In the present study, the percentage of viable sperm, non-viable sperm, viable intact sperm, viable damage sperm and viable damage and non-viable sperm was ranged from 75.12 to $82.28,17.72$ to $30.66,58.55$ to $78.48,3.80$ to 10.80 and 21.52 to 41.45 respectively. These results were agreement with Garner et al., (1986) reported that the percentage of intact acrosomes was ranged from 70 to 90 in cryopreserved bovine semen from 14 bulls. 
The percentages (Mean $\pm \mathrm{SD}$ ) of viable, acrosome intact spermatozoa as assessed by by dual staining and triple staining immediately after thawing (0h) was $63.57 \pm$ 12.44 and $59.36 \pm 12.38$ respectively (Nagy et al., 2003)

From the present study, it was concluded that the flowcytometry based sperm evaluation is a fast, accurate, highly sensitive and highly repeatable technique.

\section{Acknowledgments}

Part of M.V. Sc thesis submitted to Tamil Nadu Veterinary and Animal Sciences University, MMC, Chennai - 600 051. This study was financially supported by IVF selffinancing scheme, Dept. of ABT, MVC. The authors are thankful to TANUVAS for providing the facilities to carrying out the research work. The authors are acknowledged to Dr. P. Raja, Assistant Professor for his help rendered for preparation of manuscripts.

\section{References}

Alessandra, G., L.G. Michele, F. Angela, P. Flavia, N. Michele, D.A.M. Elena and M. Fiorenza, 2010. Assessment of viability, chromatin structure stability, mitochondrial function and motility of stallion fresh sperm by using objective methodologies. J. Cell Anim. Biol., 2010. 4: 34-41.

Bochenek, M., Z. Smorag and J. Pilch, 2001. Sperm chromatin structure assay of bulls qualified for artificial insemination. Theriogenology, 56: 55767.

Christensen, P., J.P. Stenvang, and W.L. Godfrey. 2004. A flow cytometric method for rapid determination of sperm concentration and viability in mammalian and avian semen. Androl, 25: 255-264.
Evenson, D.P., Z. Darzynkiewicz and M.R. Melamed, 1980. Relation of mammalian sperm chromatin heterogeneity to fertility. Science, 210: 1131-1133.

Evenson, D.P., Z. Darzynkiewicz, and M.R. Melamed, 1982. Simultaneous measurement by flow cytometry of sperm cell viability and mitochondrial membrane potential related to cell motility. J. Histochem. Cytochem, 30: 279-80.

Garner, D.L., and L.A. Johnson, 1995. Viability assessment of mammalian sperm using SYBR-14 and propidium iodide. Biol. Reprod., 53: 276-284.

Garner, D.L., D. Pinkel, L.A. Johnson and M.M. Pace, 1986. Assessment of spermatozoal function using dual fluorescent staining and flow cytometric analyses. Biol. ReprodI., 34: 127-138.

Garner, D.L., L.A. Johnson, S.T. Yue, B.L. Roth, and R.P. Haugland, 1994. Dual DNA staining assessment of bovine sperm viability using SYBR-14 and propidium iodide. J. Androl., 15: 620629.

Gillan, L., G. Evans, W.M.C Maxwell, 2005. Flow cytometric evaluation of sperm parameters in relation to fertility potential. Theriogenology, 63: 445-457.

Graham, J.K., 2001. Assessment of sperm quality: a flow cytometric approach. Anim. Reprod. Sci., 68: 239-247.

Graham, J.K., E. Kunze, and R.H. Hammerstedt, 1990. Analysis of sperm cell viability, acrosomal integrity and mitochondrial function using flow cytometry. Biol. Reprod., 43: 55-64.

Hossain, M.S., Johannisson, A; Wallgren, M; Nagy, S; Siqueira, AP and RodriguezMartinez, H (2011b). Flow cytometry for the assessment of animal sperm integrity and functionality: state of the art. Asian J. Androl., 13: 406-419.

Kennedy, C., and P. Sutovsky, 2011. New flow cytometric methods for evaluating 
bull semen. Proceedings, Applied Reproductive Strategies in Beef Cattle August 31st-September 1st, 2011; Joplin, MO

Loken, M.R., 1980. Simultaneous quantitation of hoechst 33342 and immunofluorescence on viable cells using a fluorescence activated cell sorter. Cytometry. 1(2): 136-142

Melamed, M. R., Mullaney, P. F., and Mendelsohn, M. L. (eds.), 1979, Flow Cytometry and Sorting, Wiley, New York.

Nagy, S., J. Jansen, E.K. Topper, and B.M. Gadella, 2003. A triple-stain flow cytometric method to assess plasmaand acrosome-membrane integrity of cryopreserved bovine sperm immediately after thawing in presence of egg-yolk particles. Biol. Reprod. 68: 1828-1835.

Petrunkina, A.M., D. Waberski, A.R. GunzelApel and E. Topfer-Petersen, 2007:
Determinants of sperm quality and fertility in domestic species. Reproduction, 134: 3-17.

Purdy, P.H., and J.K. Graham, 2004. Effect of adding cholesterol to bull sperm membranes on sperm capacitation, the acrosome reaction and fertility. Biol. Reprod.71: 522-7.

Silva, P., and B. Gadella, 2006. Detection of damage in mammalian sperm cells. Theriogenology, 65: 958-78.

Thomas, C.A., D.L. Garner, J.M. DeJarnette, and C.E. Marshall, 1997. Fluorometric assessments of acrosomal integrity and viability in cryopreserved bovine spermatozoa. Biol. Reprod., 56: 991998.

Yanagimachi, R., 1981. Mechanisms of fertilization in mammals. In: Mastroianni L, Biggers JD, editors. Fertilization and embryonic development in vitro. Plenum. Publ., p. 81-182.

\section{How to cite this article:}

Rajaram, V., A. Palanisammi, V. Maroudam, S.N. Sivaselvam and Kumanan, K. 2017. Evaluation of Sperm Viability and Acrosomal Integrity by Flow Cytometry Analysis in Jersey Crossbred Bulls. Int.J.Curr.Microbiol.App.Sci. 6(10): 87-93. doi: https://doi.org/10.20546/ijcmas.2017.610.010 